\title{
Gender Disparities in Osteoporosis
}

\author{
Khaled A. Alswat
}

\begin{abstract}
Osteoporosis is a growing health concern worldwide and its complications are as prevalent as other common chronic disease complications such as hypertension and diabetes. In this review, we will discuss the role of gender in osteoporosis, especially related to peak bone mass and maturation, rate of annual bone loss, screening, prevalence of osteoporosis and its related fractures, mortality after osteoporosisrelated fracture, fracture risk predication using different technologies and the impact of gender on osteoporosis management.
\end{abstract}

Keywords: Osteoporosis; Men; Fracture and dual energy X-ray absorptiometry

\section{Introduction}

Osteoporosis is defined as a decrease in bone density that results in micro-architecture deterioration, which predisposes affected patients to fractures. It is recognized as the most common form of metabolic bone disease, with an estimated 200 million people affected worldwide [1]. Aging is one of the main risk factors for osteoporosis and osteopenia.

Clinicians believe that the decline in bone density and its complications solely affect postmenopausal women, which may create health disparities. However, osteoporosis and its complications affect both genders but at different ages and rates [2]. Osteoporosis is four times more common in women than in men, but some evidence indicates that men tend to have more osteoporosis-related complications [3, 4].

\section{Peak Bone Mass and Maturation}

To understand gender differences in osteoporosis, the physiology of bone maturation and the skeletal growth must first be understood. Boys usually achieve similar or higher bone density but at a later age compared with girls, which was shown in a Swiss study that assessed the bone mass in 207 healthy

Manuscript accepted for publication March 01, 2017

Department of Internal Medicine, Taif University School of Medicine, Taif, Saudi Arabia. Email: kalswat@hotmail.com

doi: https://doi.org/10.14740/jocmr2970w girls and boys, aged 9 - 18 years [5]. They determined the bone density and content using dual energy X-ray absorptiometry (DXA) at three major sites: the lumbar spine, femoral neck and mid-femoral shaft. Boys compared with girls showed a significant age-related delay in lumbar spine density irrespective of puberty, but at the age of 18 years, both boys and girls reached a similar bone density. Lumbar spine bone content and femoral shaft bone density were significantly higher at age 18 years in boys, which was related to a reduction in bone mass growth that was observed after the age of 15 years in girls. Femoral neck bone density was not significantly higher in boys at age 18 years compared with girls. Some weaknesses of this study were that it was limited to the Caucasian population, the sample size was small and it was not controlled for other important variables such as maternal vitamin $\mathrm{D}$, which has been shown to impact the peak bone maturation [6]. The observed difference in bone mineral density (BMD) may be caused by an increase in the bone size and this is also supported by similar volumetric bone density observed between both genders $[7,8]$.

Information on the impact of activity and nutrition on the skeletal maturation is limited. A study evaluated the impact of diet and physical activity on bone density in the lumbar spine, the entire femur and the distal third of the radius using a DXA scan in a sample of 51 male and 75 female students, aged 19 - 25 years [9]. Bone density was higher in males at the three measured sites compared to females, with males achieving peak density later than females, especially in the lumbar spine. This difference was not explained by varying nutrition or the level of physical activity. However, physical activity and nutrition play a role in osteoporosis prevention [10].

Males tend to have a higher lean mass percentage compared with females, which was shown in a small study of a group of 36 healthy males and females with a comparable body size and a mean age of 18 years. Controlling for lean mass, males had $8 \%$ higher bone density at the hip than females [11]. In a subset of males and females in the same study who were matched for hip bone area, males still had greater bone mineral density and content at the hip.

In summary, males tend to have higher bone density and content and they achieve it at later age compared with females. This difference is not explained by nutrition, level of physical activity, body weight or lean mass, but it may be because of the bone size.

\section{Bone Loss}

Gradual bone loss is common with aging and here we will 
evaluate the role of gender in the rate of annual loss, age of onset, risk factors and the bone markers.

Women tend to have younger onset of bone loss compared with men. A longitudinal study, which included 769 men and women 60 years of age and older, evaluated the annual bone loss using DXA scans at an interval of 2.5 years. The estimated annual bone loss at the femoral neck was $0.82 \%$ per year for men and $0.96 \%$ per year for women, which was statistically significant, but there was no significant loss at the lumbar spine in either group, likely because of coexistent osteoarthritis [12]. In the same study, the age range where the rapid decline occurred was 74 - 79 years for men compared with 65 - 69 years for women.

Women also tend to lose bone at a faster rate, which was positively correlated with weight loss in both genders and with smoking in men. The Framingham Osteoporosis Study evaluated the BMD at the hip, lumbar spine and the radius in 800 elderly men and women with mean age of 74 years [13]. They showed that the average 4-year bone loss at all sites was $0.2-3.6 \%$ for men compared with $3.4-4.8 \%$ for women. This study also showed that weight loss for both genders was significantly associated with osteoporosis, while men who smoked at baseline were more likely to lose BMD at the hip than women.

Bone loss markers and periosteal apposition may explain the difference that is seen in the amount of the bone loss between genders. A small study evaluated the bone turnover markers in 28 healthy elderly men and women; there was no gender difference in bone formation markers but men tended to have higher parathyroid hormone and lower urinary N-telopeptide compared with women [14]. The ratio of the periosteal to the endosteal bone is an important factor in bone strength. Men, to a greater degree than women, lose more endosteal bone but men gain more periosteal bone, which results in a net loss of bone in men [15].

Estrogen deficiency plays an important role in osteoporosis development for both genders, and it is more pronounced for women and at younger (menopausal) ages compared with men $[16,17]$. It is been estimated that approximately $20 \%$ of the elderly men with osteoporosis have hypogonadism [18].

In summary, men and women tend to lose bone but women tend to lose bone at younger age and at a more rapid pace than men and they also have higher bone resorption markers. Smoking and weight loss are important modifiable risk factors that should be targeted when such patients are evaluated. The periosteal gain in men ameliorates the endosteal bone loss and results in more bone strength compared with women.

\section{Prevalence of Osteopenia and Osteoporosis}

The World Health Organization (WHO) established a classification for BMD (using DXA) in which the T-score of 2.5 $\mathrm{SD}$ or more below the young-adult mean BMD is defined as osteoporosis [19]. The National Health and Nutrition Examination Survey (NHANES) that was performed from 1988 to 1994 evaluated hip bone density using a DXA scan for men and women aged $\geq 50$ years. The prevalence of hip osteope- nia and osteoporosis was $18 \%$ and $2 \%$ for men compared with $56 \%$ and $16 \%$ for women, respectively [20].

The NHANES 2005 - 2008 study that evaluated the bone density of the hip and lumbar spine showed that the prevalence of osteopenia and osteoporosis at either site was 38\% and $4 \%$ for men compared with $61 \%$ and $16 \%$ for women, respectively [21]. Comparing data from both NHANES studies, the prevalence of osteopenia and osteoporosis was doubled for men while it was remained about the same for women. This is likely because the screened population in both studies included a much older male population. A recent study showed the comparable prevalence of osteoporosis for men aged 70 years or older and women aged 65 years [22].

The age-specific increase in the prevalence of low bone density according to the recent NHANES data showed a rapid increase in the prevalence of osteopenia and osteoporosis in both genders but at different ages and magnitudes [21]. In women, the prevalence of osteopenia rapidly increased at age of 60 years and that of osteoporosis rapidly increased (tripled) at age of 70 years. In men, prevalence increased at the age of 80 years and the rate of osteoporosis doubled.

In summary, women aged 50 years or older have a four times higher rate of osteoporosis and a two times higher rate of osteopenia compared with men.

\section{Screening Recommendations}

Screening recommendations from health-related societies and organizations vary and few have clear recommendations for osteoporosis screening in men; most recommend screening for any men aged 70 years and older (Table 1).

Despite these recommendations, few studies showed what can be best described as disparities for males regarding the osteoporosis screening. In a study that evaluated 8,262 patients who were eligible for osteoporosis screening based on the age criteria, only patients who had at least one health maintenance examination since becoming eligible for screening based on age were included, to ensure that the physician had the chance to discuss preventive services [22]. They found that $60 \%$ of the women and only $18.4 \%$ of the men had undergone DXA for osteoporosis screening.

Another study evaluated the osteoporosis screening rate for 310 male patients, aged 70 years or older, in a primary care clinic setting [23]. Only $11 \%$ of the eligible men, based on age, had undergone a DXA scan and the majority of the screened men were 80 - 89 years of age, while none of the men aged $>$ 90 years had undergone a DXA scan.

A retrospective study evaluated the rate of osteoporosis screening for high-risk patients, including 95 men and 344 women aged 50 years and older who had a distal radial fracture [24]. They found that $10 \%$ of the women and only $9 \%$ of the men had undergone a DXA scan for osteoporosis.

Another study, which included patients aged 65 years or older, evaluated the rate of osteoporosis screening with DXA scan after a hip fracture diagnosis and showed that $12.1 \%$ of women and only $5.4 \%$ of the men underwent a DXA scan [25]. A similar study evaluated the screening rate among 363 pa- 
Table 1. Summary of the Osteoporosis Screening Recommendations

\begin{tabular}{lll}
\hline \multirow{2}{*}{ Society/organization } & \multicolumn{2}{c}{ Recommendations } \\
\cline { 2 - 3 } & Women & Men \\
\hline $\begin{array}{l}\text { National Osteoporosis Foundation } \\
\text { International Society for Clinical Densitomety }\end{array}$ & $\begin{array}{l}\text { All women }>65 \text { years and postmenopausal } \\
\text { Endocrine Society }\end{array}$ & $\begin{array}{l}\text { All men }>70 \text { years or men aged } 50 \text { - } 69 \\
\text { years with risk factors }\end{array}$ \\
$\begin{array}{l}\text { World Health Organization } \\
\text { American Association of Clinical Endocrinologist } \\
\text { United States Preventive Services Task Force }\end{array}$ & Women $>65$ years old & No recommendation \\
$\begin{array}{l}\text { American Academy of Family Physicians } \\
\text { Canadian Osteoporosis Society }\end{array}$ & & Men $>65$ years \\
$\begin{array}{l}\text { American College of Physician } \\
\text { UK National Osteoporosis Guideline Group }\end{array}$ & Women $>65$ years & Assess the risk factors and consider DXA scan for those at risk for osteoporosis \\
\hline
\end{tabular}

tients aged 50 years and older who had history of atraumatic hip fracture, and only $11 \%$ of men and $27 \%$ of women had undergone a DXA scan within 5 years before the fracture [26]. It is still unclear why men tend to be offered less screening than women. The older age of onset, the high amount of comorbidities that such patients may have, the physician's and patient's lack of awareness and the insurance coverage in part may explain this phenomenon [23].

In summary, clinicians need to improve osteoporosis screening among eligible individuals, and in general, men tend to be under-screened for osteoporosis compared with women. Age may play a main role in such differences seen in osteoporosis screening.

\section{Screening Tools}

Several technologies are currently available to assess bone density, but few have been validated to predict the future risk of fractures. The most widely available, well-validated tool to screen for osteoporosis and predict the risk of future fractures for both genders is the central DXA scan [27]. The central DXA device measures the BMD at the hip, distal radius and spine, while peripheral DXA measures BMD at the wrist, heel or finger. Other than central DXA, other technologies like pDXA and quantitative CT scan may be used to screen for osteoporosis, but they are limited to the age and the gender group for which they were validated. In addition, these technologies other than cDXA scan should not be used for treatment monitoring until more data are published.
The currently available screening tools have been validated to predict the risk of the future fracture for postmenopausal women, while only the central DXA and the quantitative ultrasound have been validated for men (Table 2).

Although The Fracture Risk Assessment Tool (FRAX) is widely used to predict the risk of future fractures, it has been shown to underestimate the risk of fractures in men compared with women [28, 29]. However, it is still useful and recommended to be used for fracture risk predictions in men and women [30].

In summary, central DXA scan still is the best modality to diagnose osteoporosis and to predict the risk of the future fractures for men and women. More studies are needed to assess the validity of the other tools to be used routinely in eligible men who are at risk. The FRAX calculator can be used to predict the fracture risk, but clinicians should be aware that it underestimates the risk in men.

\section{Fractures}

Before the age of 50 years, men tend to have more fractures than women, and these fractures mainly involve the limbs and result from a higher frequency of trauma from sports activities [31]. In a study that evaluated the gender-specific fracture site among 5 million adults aged 20 years and older, the most common fracture was the carpal bone in men compared with forearm fractures for women [31]. In the same study, the estimated lifetime risk was $20.7 \%$ for men compared with $53.2 \%$ for women.

Table 2. Fracture Risk Prediction Using Different Technologies in Men and Women

\begin{tabular}{lll}
\hline Technology & Fractures risk prediction in men & Fractures risk prediction in women \\
\hline Quantitative ultrasound (QUS) & $\begin{array}{l}\text { Non-vertebral and hip fractures } \\
\text { only (men }>65 \text { years old) }\end{array}$ & Hip, vertebral and global fractures (postmenopausal only) \\
$\begin{array}{l}\text { Peripheral DXA (pDXA) } \\
\begin{array}{l}\text { Quantitative computer } \\
\text { tomography (QCT) }\end{array}\end{array}$ & $\begin{array}{l}\text { Lack of evidence } \\
\text { Leripheral QCT }(\mathrm{pQCT})\end{array}$ & Vertebral and global fractures- weaker than QUS (postmenopausal only) \\
\hline
\end{tabular}


For the vertebral fractures, the fracture incidence rapidly rises for women at the age of 55 years compared with an age of 65 years for men. For the hip fractures, the fracture incidence rapidly rises at the age of 65 years for women compared with the age of 75 years for men [32].

The increased fractures that are observed in women may be explained by their smaller bone size, early onset increased bone resorption and fall risk. Larger bones in men are somewhat protective and increase the bone strength compared with women [33]. The risk of falls increases as patients age, and by the age of 85 years, it is estimated to reach to 138.5 for men and 158.8 for women per 1,000 patients [34]. Higher androgen levels are associated with a decreased risk of falls [35].

A DXA scan as a predictor for the non-vertebral and hip fractures was evaluated in a population-based cohort study conducted in 1990 - 1993, which enrolled 7,806 men and women aged 55 years and older [36]. Men tended to have fractures at non-vertebral sites with a higher bone density compared with women, while BMD is comparable in both genders for hip fractures. This can be explained by the degenerative changes in men, which can falsely increase the BMD. We conclude that a DXA scan alone may not be a sensitive enough tool to predict non-vertebral fractures for men aged 50 years and older.

In summary, women tend to have fractures about $5-10$ years earlier than men and have a higher lifetime risk of fractures. The excess fractures observed in women may be explained by their smaller bone size and their increased risk of falls. In addition, men usually have fractures at a higher bone density and at non-vertebral sites.

\section{Mortality After Fractures}

Overall, men have a shorter life expectancy compared with women [37]. Men also have a higher mortality rate after sustaining a hip fracture compared with women. The risk of mortality after a hip fracture was assessed in a population-based prospective study that included 1,338 women and 487 men with hip fractures, aged 50 years and older, who were matched with 11,086 and 8,141 controls, respectively [38]. In the first year and irrespective of age, men had a higher mortality rate after hip fracture compared with women $(31 \%$ and $17 \%$, respectively). Compared with the control and for patients aged $<$ 75 years, the relative risk of mortality was 4.2 for men and 3.3 for women, and for those aged $>85$ years, the relative risk of mortality was 3.1 for men and 1.6 for women.

More recently, a nationwide Danish registry-based cohort study that included $>41,000$ patients with hip fracture from 1999 to 2002 with a follow-up period until 2005, was published [39]. Men had fractures at an age that was 4 years younger than of women, with a cumulative mortality at 1 year of $37.1 \%$ in men and $26.4 \%$ in women compared with the general population. Long-term survival, which was assessed after controlling for age, medications, fracture site and comorbidities, showed that men had a $70 \%$ higher risk of mortality compared with women, which was statically significant.

Infection is one possible explanation for the observed mortality rate. One study evaluated the possible predisposing factors for such excess mortality after hip fracture and concluded that the preexisting comorbidity, type of fracture, type of surgery and operative complications did not explain the observed gender difference [40]. However, infection, especially septicemia and pneumonia, may explain the higher risk of mortality in men who have a greater magnitude of infection. When they adjusted for the infection, the risk of mortality was similar for both genders.

Both intravenous and oral bisphosphonate has been shown to independently reduce the risk of mortality when instituted after a patient's sustained hip fracture and for frail older patients [41, 42]. Men tended to receive less bisphosphonate prescriptions compared with women after hip fractures [25].

In summary, regardless of age or comorbidities, men have a higher risk of mortality following hip fracture. Infection and poor medical management may explain the higher rate of mortality observed in men.

\section{Medical Management}

While all of the currently available agents for osteoporosis management are approved for postmenopausal women, most are validated for men with osteoporosis. For men with osteoporosis, the preferred bisphosphonate agents are alendronate, zoledronic acid and risedronate [43-45].

Prevention and management of osteoporosis after fractures is not optimal for both genders, but it is worse for men. A study was performed that included 615 patients aged 55 years or older who are on prednisone $(\geq 7.5 \mathrm{mg}$ for at least 3 months), and osteoporosis prophylaxis management who were evaluated between 2001 and 2005 [46]. In 2005, osteoporosis prevention treatment in women improved significantly while that in men was unchanged compared with 2001. In 2005, women received more osteoporosis prevention treatment $(\mathrm{Ca}$, vitamin $\mathrm{D}$, and/or bisphosphonate) compared with men ( $72 \%$ vs. $45 \%$ ) and bisphosphonate was used in their treatment more frequently than for men (61\% vs. $39 \%)$.

The improvement of bisphosphonate use within 6 months from the osteoporosis-related fractures was assessed in a retrospective cohort study that included 1,171 men aged 65 years and older between 1998 and 2001 [47]. There was an increase in bisphosphonate use, but it did not reach statistical significance (13\% in 1998 compared to $18 \%$ in 2001). Men were also undertreated after distal radial fractures and the male gender is an independent predictor for subsequent treatment failure after the fracture [24].

Between 2000 and 2010, 417 patients with the discharging diagnosis of hip fracture were analyzed [25]. Men were less likely to receive osteoporosis treatment (8\%) compared with women (23.3\%). Another study evaluated the percent of patients who received the appropriate medical treatment after fragile hip fractures, 1 - 5 years after discharged. Only $9 \%$ of men compared with $48 \%$ of women received the appropriate medical treatment [26].

In summary, men were less likely to receive medical treatment for osteoporosis prevention and treatment even when they sustained fractures. 


\section{Conclusion}

Men have a higher BMD at the hip and a higher bone mineral content at the lumbar spine. Women start losing bone at an earlier age and at a faster rate than men. Women $\geq 50$ years of age have a four times higher rate of osteoporosis and a two times higher rate of osteopenia, and they tend to have fractures $5-10$ years earlier compared with men. Men usually have fractures at a higher bone density, especially at the lumbar spine, and they tend to have a higher mortality risk after the hip fracture. Men are under-screened for osteoporosis and they are also undertreated even when they have fractures.

\section{Conflicts of Interest}

None.

\section{Funding}

None.

\section{References}

1. Cooper C, Campion G, Melton LJ, 3rd. Hip fractures in the elderly: a world-wide projection. Osteoporos Int. 1992;2(6):285-289.

2. Osteoporosis prevention, diagnosis, and therapy. JAMA. 2001;285(6):785-795.

3. Center JR, Nguyen TV, Schneider D, Sambrook PN, Eisman JA. Mortality after all major types of osteoporotic fracture in men and women: an observational study. Lancet. 1999;353(9156):878-882.

4. Feldstein A, Elmer PJ, Orwoll E, Herson M, Hillier T. Bone mineral density measurement and treatment for osteoporosis in older individuals with fractures: a gap in evidence-based practice guideline implementation. Arch Intern Med. 2003;163(18):2165-2172.

5. Bonjour JP, Theintz G, Buchs B, Slosman D, Rizzoli R. Critical years and stages of puberty for spinal and femoral bone mass accumulation during adolescence. J Clin Endocrinol Metab. 1991;73(3):555-563.

6. Zhu K, Whitehouse AJ, Hart PH, Kusel M, Mountain J, Lye S, Pennell C, et al. Maternal vitamin D status during pregnancy and bone mass in offspring at 20 years of age: a prospective cohort study. J Bone Miner Res. 2014;29(5):1088-1095.

7. Lu PW, Cowell CT, SA LL-J, Briody JN, HowmanGiles R. Volumetric bone mineral density in normal subjects, aged 5-27 years. J Clin Endocrinol Metab. 1996;81(4):1586-1590.

8. Seeman E. Pathogenesis of bone fragility in women and men. Lancet. 2002;359(9320):1841-1850.

9. Avdagic SC, Baric IC, Keser I, Cecic I, Satalic Z, Bobic J, Gomzi M. Differences in peak bone density between male and female students. Arh Hig Rada Toksikol.
2009;60(1):79-86.

10. Anderson JJ, Rondano P, Holmes A. Roles of diet and physical activity in the prevention of osteoporosis. Scand J Rheumatol Suppl. 1996;103:65-74.

11. Nieves JW, Formica C, Ruffing J, Zion M, Garrett P, Lindsay R, Cosman F. Males have larger skeletal size and bone mass than females, despite comparable body size. $\mathrm{J}$ Bone Miner Res. 2005;20(3):529-535.

12. Jones G, Nguyen T, Sambrook P, Kelly PJ, Eisman JA. Progressive loss of bone in the femoral neck in elderly people: longitudinal findings from the Dubbo osteoporosis epidemiology study. BMJ. 1994;309(6956):691-695.

13. Hannan MT, Felson DT, Dawson-Hughes B, Tucker KL, Cupples LA, Wilson PW, Kiel DP. Risk factors for longitudinal bone loss in elderly men and women: the Framingham Osteoporosis Study. J Bone Miner Res. 2000;15(4):710-720.

14. Greenspan SL, Dresner-Pollak R, Parker RA, London D, Ferguson L. Diurnal variation of bone mineral turnover in elderly men and women. Calcif Tissue Int. 1997;60(5):419-423.

15. Seeman E. During aging, men lose less bone than women because they gain more periosteal bone, not because they resorb less endosteal bone. Calcif Tissue Int. 2001;69(4):205-208.

16. Falahati-Nini A, Riggs BL, Atkinson EJ, O'Fallon WM, Eastell R, Khosla S. Relative contributions of testosterone and estrogen in regulating bone resorption and formation in normal elderly men. J Clin Invest. 2000;106(12):15531560.

17. Gennari L, Khosla S, Bilezikian JP. Estrogen and fracture risk in men. J Bone Miner Res. 2008;23(10):1548-1551.

18. Center JR, Nguyen TV, Sambrook PN, Eisman JA. Hormonal and biochemical parameters in the determination of osteoporosis in elderly men. J Clin Endocrinol Metab. 1999;84(10):3626-3635.

19. Assessment of fracture risk and its application to screening for postmenopausal osteoporosis. Report of a WHO Study Group. World Health Organ Tech Rep Ser. 1994;843:1-129.

20. The third National Health and Nutrition Examination Survey 1988-94, Center of Disease Control website.

21. The National Health and Nutrition Examination Survey 2005-08, Center of Disease Control website.

22. Alswat K, Adler SM. Gender differences in osteoporosis screening: retrospective analysis. Arch Osteoporos. 2012;7:311-313.

23. Lim SY, Lim JH, Nguyen D, Okamura R, Amiri HM, Calmes M, Nugent K. Screening for osteoporosis in men aged 70 years and older in a primary care setting in the United States. Am J Mens Health. 2013;7(4):350-354.

24. Harper CM, Fitzpatrick SK, Zurakowski D, Rozental TD. Distal radial fractures in older men. A missed opportunity? J Bone Joint Surg Am. 2014;96(21):1820-1827.

25. Antonelli M, Einstadter D, Magrey M. Screening and treatment of osteoporosis after hip fracture: comparison of sex and race. J Clin Densitom. 2014;17(4):479-483.

26. Kiebzak GM, Beinart GA, Perser K, Ambrose CG, Siff SJ, Heggeness MH. Undertreatment of osteoporosis in men 
with hip fracture. Arch Intern Med. 2002;162(19):22172222.

27. International Society for Clinical Densitometry (ISCD) 2013 official statement. JCD;16(4):455-467. http://www. iscd.org/official-positions/2013-iscd-official-positionsadult/.

28. Sandhu SK, Nguyen ND, Center JR, Pocock NA, Eisman JA, Nguyen TV. Prognosis of fracture: evaluation of predictive accuracy of the FRAX algorithm and Garvan nomogram. Osteoporos Int. 2010;21(5):863-871.

29. Kanis JA, Oden A, Johnell O, Johansson H, De Laet C, Brown J, Burckhardt P, et al. The use of clinical risk factors enhances the performance of BMD in the prediction of hip and osteoporotic fractures in men and women. Osteoporos Int. 2007;18(8):1033-1046.

30. Watts NB, Adler RA, Bilezikian JP, Drake MT, Eastell R, Orwoll ES, Finkelstein JS. Osteoporosis in men: an Endocrine Society clinical practice guideline. J Clin Endocrinol Metab. 2012;97(6):1802-1822.

31. van Staa TP, Dennison EM, Leufkens HG, Cooper C. Epidemiology of fractures in England and Wales. Bone. 2001;29(6):517-522.

32. Cooper C, Melton LJ, 3rd. Epidemiology of osteoporosis. Trends Endocrinol Metab. 1992;3(6):224-229.

33. Wang XF, Duan Y, Beck TJ, Seeman E. Varying contributions of growth and ageing to racial and sex differences in femoral neck structure and strength in old age. Bone. 2005;36(6):978-986.

34. Sattin RW, Lambert Huber DA, DeVito CA, Rodriguez JG, Ros A, Bacchelli S, Stevens JA, et al. The incidence of fall injury events among the elderly in a defined population. Am J Epidemiol. 1990;131(6):1028-1037.

35. Orwoll E, Lambert LC, Marshall LM, Blank J, BarrettConnor E, Cauley J, Ensrud K, et al. Endogenous testosterone levels, physical performance, and fall risk in older men. Arch Intern Med. 2006;166(19):2124-2131.

36. Schuit SC, van der Klift M, Weel AE, de Laet CE, Burger H, Seeman E, Hofman A, et al. Fracture incidence and association with bone mineral density in elderly men and women: the Rotterdam Study. Bone. 2004;34(1):195-202.

37. Branch LG, Guralnik JM, Foley DJ, Kohout FJ, Wetle TT, Ostfeld A, Katz S. Active life expectancy for 10,000 Caucasian men and women in three communities. J Gerontol. 1991;46(4):M145-150.
38. Forsen L, Sogaard AJ, Meyer HE, Edna T, Kopjar B. Survival after hip fracture: short- and long-term excess mortality according to age and gender. Osteoporos Int. 1999;10(1):73-78.

39. Kannegaard PN, van der Mark S, Eiken P, Abrahamsen B. Excess mortality in men compared with women following a hip fracture. National analysis of comedications, comorbidity and survival. Age Ageing. 2010;39(2):203209.

40. Wehren LE, Hawkes WG, Orwig DL, Hebel JR, Zimmerman SI, Magaziner J. Gender differences in mortality after hip fracture: the role of infection. J Bone Miner Res. 2003;18(12):2231-2237.

41. Beaupre LA, Morrish DW, Hanley DA, Maksymowych WP, Bell NR, Juby AG, Majumdar SR. Oral bisphosphonates are associated with reduced mortality after hip fracture. Osteoporos Int. 2011;22(3):983-991.

42. Sambrook PN, Cameron ID, Chen JS, March LM, Simpson JM, Cumming RG, Seibel MJ. Oral bisphosphonates are associated with reduced mortality in frail older people: a prospective five-year study. Osteoporos Int. 2011;22(9):2551-2556.

43. Orwoll E, Ettinger M, Weiss S, Miller P, Kendler D, Graham J, Adami S, et al. Alendronate for the treatment of osteoporosis in men. N Engl J Med. 2000;343(9):604-610.

44. Ringe JD, Faber H, Farahmand P, Dorst A. Efficacy of risedronate in men with primary and secondary osteoporosis: results of a 1-year study. Rheumatol Int. 2006;26(5):427-431.

45. Orwoll ES, Miller PD, Adachi JD, Brown J, Adler RA, Kendler D, Bucci-Rechtweg C, et al. Efficacy and safety of a once-yearly i.v. Infusion of zoledronic acid $5 \mathrm{mg}$ versus a once-weekly $70-\mathrm{mg}$ oral alendronate in the treatment of male osteoporosis: a randomized, multicenter, double-blind, active-controlled study. J Bone Miner Res. 2010;25(10):2239-2250.

46. Duyvendak M, Naunton M, Atthobari J, van den Berg PB, Brouwers JR. Corticosteroid-induced osteoporosis prevention: longitudinal practice patterns in The Netherlands 2001-2005. Osteoporos Int. 2007;18(10):1429-1433.

47. Feldstein AC, Nichols G, Orwoll E, Elmer PJ, Smith DH, Herson M, Aickin M. The near absence of osteoporosis treatment in older men with fractures. Osteoporos Int. 2005;16(8):953-962. 